\title{
An Intervention with Physical Activity and Lifestyle Counseling Improves Health-Related Quality of Life and Shows Small Improvements in Metabolic Risks in Persons with Psychosis
}

\author{
Rikard Wärdig, Anniqa Foldemo, Sally Hultsjo, Torbjörn Lindström and Margareta \\ Bachrach-Lindström
}

\section{Linköping University Post Print}

\section{Tweet}

N.B.: When citing this work, cite the original article.

Original Publication:

Rikard Wärdig, Anniqa Foldemo, Sally Hultsjo, Torbjörn Lindström and Margareta BachrachLindström, An Intervention with Physical Activity and Lifestyle Counseling Improves HealthRelated Quality of Life and Shows Small Improvements in Metabolic Risks in Persons with Psychosis, 2016, Issues in Mental Health Nursing, (37), 1, 43-52.

http://dx.doi.org/10.3109/01612840.2015.1092187

Copyright: Informa Healthcare

$\underline{\mathrm{http}: / / \text { informahealthcare.com/ }}$

Postprint available at: Linköping University Electronic Press

http://urn.kb.se/resolve?urn=urn:nbn:se:liu:diva-125688 
An intervention with physical activity and lifestyle counseling improves health-related quality of life and shows small improvements in metabolic risk factors in persons with psychosis

Rikard Wärdig, PRN, PhD student ${ }^{1}$, Torbjörn Lindström, MD, Adjunct Professor ${ }^{1,3}$, Anniqa Foldemo, PRN, PhD ${ }^{1}$, Sally Hultsjö, PRN, PhD ${ }^{2,4}$, Margareta Bachrach-Lindström PhD, Associate Professor ${ }^{1}$

1. Department of Medical and Health Sciences, Linköping University, Linköping, Sweden.

2. Psychiatric Clinic, Ryhov County Hospital, Jönköping, Sweden.

3. Department of Endocrinology and Department of Medical and Health Sciences, Linköping University, Linköping, Sweden.

4. School of Health and Welfare, University of Jönköping; Sweden.

\section{Corresponding author:}

Rikard Wärdig, Department of Medical and Health Sciences, Division of Nursing Science, Linköping University, 58183 Linköping, Sweden. E-mail: rikard.wardig@liu.se. Telephone:+46 13286850 


\section{Abstract}

General purpose: To study the effects of a lifestyle intervention on health-related quality of life (HRQoL) and metabolic risk factors in persons with psychosis. Methodology: A longitudinal intervention study with a matched reference sample. Results: HRQoL measured by the EQ-VAS improved from 57.6 to $63.3(17.8)$ in the intervention group $(p=0.05)$. The HDL cholesterol concentration increased from 1.03 to $1.11(0.19) \mathrm{mmol} / \mathrm{l}$ in the intervention group $(p=0.02)$. There was no significant change in body weight. Conclusion: A lifestyle intervention based on group meetings improves HRQoL in patients with psychosis. There are also small improvements in metabolic risk factors.

Keywords: Health-related quality of life, lifestyle intervention, metabolic syndrome, physical health, psychosis. 


\section{Introduction}

Persons with psychosis often die an early death due to lifestyle- related diseases such as cardiovascular disease, as a consequence of the metabolic syndrome. Besides severe psychiatric symptomatology and feelings of stigma and isolation (Mestdagh and Hansen, 2014), these persons frequently have substantial problems with physical health. Addressing physical health creates challenges for mental health care professionals (de Hert et al., 2011). Mental health care professionals need to see beyond psychiatric symptoms, which have historically been the main focus for treatment (Heald, 2010). The physical health risks among persons with psychosis require interventions targeting lifestyle (Edward et al., 2010).

Previous research has shown that persons with psychiatric disorders and psychotic disorders report lower health-related quality of life (HRQoL) compared with the general population (Foldemo et al., 2014, Saarni et al 2007). A link has also been demonstrated between the presence of risk factors for metabolic syndrome and lower HRQoL (Foldemo et al., 2014, Roohafza et al., 2012). Health-related quality of life is the part of the quality of life concept that can potentially be influenced by health and health care activities (Saarni et al., 2010). In psychiatric care, there is now more focus on concepts such as autonomy and integrity; as a result, quality of life (QoL) has become a more important issue (Saarni et al., 2010). It has long been recognized that QoL can be viewed as an important treatment goal as complete recovery from a psychotic disorder is unlikely (Baker and Intaglita, 1982).

The metabolic syndrome is highly prevalent in persons with psychosis. An overview of eleven studies examining the prevalence of metabolic syndrome in persons with schizophrenia revealed that between 23 and $68 \%$ had metabolic syndrome, according to one of the established definitions (Meyer and Stahl, 2009). In a Swedish study by Foldemo et al. (2014), almost half of the persons with psychosis met the criteria for metabolic syndrome, which is defined as increased waist circumference, elevated blood pressure, fasting glucose and triglycerides, together with reduced HDL cholesterol (Alberti et al., 2009). The increased risk for developing metabolic syndrome is 
multifactorial (Daumit et al., 2013). Psychotic disorders may lead to cognitive dysfunctions that can make it difficult for the person to manage nutrition, sleep, and activity (American Psychiatric Association, 2013). Medication is an additional challenge (Mitchell et al., 2012). The first treatment option is second generation antipsychotic drugs. These are shown to decrease psychotic symptoms, but also have side-effects, such as increased body weight, elevated blood-glucose and hyperlipidaemia (Rummel-Kluge et al., 2010). Combined, these factors pose a great risk for developing the metabolic syndrome and subsequently cardiovascular disease.

Identifying metabolic risk factors can prevent and delay deterioration of physical health-and reduce the risk for cardiovascular disease (Newcomer, 2006). However, the severity of the psychosis symptoms varies widely, leading to difficulties in designing interventions targeting this group (Brown and McGrath, 2011). Previous research has proposed a combination of individual and group activities (Bradshaw et al., 2005). Individualized attention and feasible goal setting (Wärdig et al., 2015, Richardson et al., 2005 a) create good conditions for behavior change. Professional support is an important prerequisite that should target the transition from thought to action (Wärdig et al., 2013) and facilitate the participants' ability to mirror themselves against so- called "healthy people" in society, by introducing activities that ordinary people do (Wärdig et al., 2015, Pickens, 1999).

Previous studies (Pearsall et al., 2014, Bonfioli et al., 2012, Happell et al., 2012, Papanastasiou, 2012, Lowe and Lubos, 2008) have demonstrated a great variety of lifestyle interventions for persons with psychosis. In the absence of convincing research findings, there is no consensus or "golden standard" of lifestyle interventions. Study design, content of interventions, and measured outcomes vary greatly (Pearsall et al., 2014, Bonfioli et al., 2012). Likewise, they have included participants with different psychiatric diagnoses, for instance, persons with psychosis (Bonfioli et al., 2012), schizophrenia (Papanastasiou, 2012), mental Illness (Happell et al., 2012), or serious mental illness (Lowe and Lubos, 2008), which may hamper the possibility to compare results between studies (Fernández-San-Martín et al., 2014). Lowe and Lubos (2008) have called for more research with 
standardized outcome measures to determine and compare the effectiveness of educational and exercise intervention, with usual treatment.

In a review of 42 articles by Happell et al., (2012), of which 16 were randomized controlled trials, involving health behavior interventions among persons with a mental illness shows great promise in relation to changes in health behaviors. A large majority of the studies demonstrated a significant weight loss. The programs reported mainly positive changes across all of the health behaviors targeted, i.e., smoking cessation, physical activity, nutrition, and alcohol abuse. A meta-analysis by Fernández-San-Martín et al., (2014) containing both randomized and non-randomized studies, showed positive differences in BMI, waist circumference, total cholesterol, blood glucose and triglycerides in the intervention groups, compared with control groups at the three- month followup. Reduced BMI was maintained at 6 and 12 months. Pearsall et al., (2014) did not come to the same beneficial conclusion in their review of eight randomized controlled studies comparing the effects of exercise intervention in persons with serious mental illness. Exercise programs could lead to improved exercise activity, but had no significant effect on symptoms of mental health or body weight.

In previous research, an absence of evaluations of more holistic healthy living programs has been noticed, and many studies have instead focused on one particular lifestyle problem (Bradshaw et al., 2005, Faulkner et al., 2003). This study presents the results of a lifestyle intervention attempting to take a multifaceted grasp of lifestyle, i.e., physical activities, as well as education in lifestyle and nutrition habits, with follow-up measurement at one year. The aim was to study the effects of a lifestyle intervention on $\mathrm{HRQ}$ oL and metabolic risk factors in persons with psychosis.

\section{Methods}

\section{Design}

A longitudinal intervention study with a matched national reference sample was performed. 


\section{The intervention}

The intervention consisted of group sessions with six to eight participants under the guidance of health coordinators (HCs). The HCs $(n=9)$ were trained nurses specialized in psychiatry $(n=3)$, physiotherapists ( $n=3)$, assistant nurses $(n=2)$, and one occupational therapist $(n=1)$. These were trained in motivational interviewing $(\mathrm{MI}$,$) and they also had vast experience of working with persons$ with psychosis through their regular jobs in outpatient psychosis care. In addition, all HCs had experience of working with this issue from previous physical group activities tailored to persons with psychosis.

The intervention took place in outpatient psychosis departments and consisted of either 9 or 20 sessions, with 18 or 26 participants respectively. Group sessions started both in the spring and the autumn and were held on a weekly basis, but with a break for the Christmas and summer vacations. In order to recruit a larger number of participants, the intervention was performed in two county councils. The participants' case managers and ordinary caregivers were informed of the design and implementation of the intervention. During the intervention, the research team had regular meetings with the $\mathrm{HCs}$ in order to synchronize the intervention based on the standardized study protocol, and thereby ensure that the adopted program was followed.

The intervention program was based on "Solutions for Wellness" (Porsdal et al., 2010), a concept developed for persons suffering from psychiatric disorders, who use psychotropic medication and have weight problems. The purpose of the intervention was to promote a healthier lifestyle, and thereby improve or maintain HRQoL and metabolic risk factors. The program focuses on theoretical education in healthy eating and physical activities. It is declared to be a flexible method and a minimum of $\mathbf{3 0}$ minutes of daily physical activity is recommended. It is emphasized that all activity counts and encourages changes in everyday life, such as choosing the stairs instead of the elevator, or walking instead of taking the bus. In addition to the program, our intervention also dealt with reducing smoking and alcohol consumption in order to promote a healthier lifestyle. 
The intervention began by identifying individual goals. The participants each received a pedometer and a food diary, which were later followed up in group sessions. Each group session included physical activity and a theoretical part with a break in the middle where different fruits were tested. The duration of the physical activity gradually increased, to up to one hour. The intensity also increased. In addition, the participants were encouraged to perform physical activity between group sessions. The physical activity involved exercise to music and sometimes walks. There was an initial plan for each session, but the HCs were free to find physical activities that captured the participants' interest on the day. However, a basic requirement was that the activity should be of such a nature that everyone could manage it, although with different intensity based on individual capacity. In order to demonstrate progress and increase the participants' motivation, body weight and waist circumference was measured regularly during the intervention.

The theoretical part included issues regarding healthy eating based on Nordic nutrition recommendations (Becker et al., 2004). It also dealt with anatomy, muscles and ligaments, together with how to achieve well-being and health. The latter could be about balancing activity and rest, or practical help with finding appropriate food in the grocery store.

The intervention had a proactive approach, meaning that absence was followed-up. The HCs called missing participants and asked why they did not attend. During these conversations they also investigated whether they could do anything to facilitate attendance to forthcoming sessions. Towards the end of the intervention, the HCs tried to find further opportunities for physical activity in the community, based on the participants' individual preferences.

\section{Measurements}

The measurements described below were conducted in both the intervention and reference sample at baseline and the one year follow-up.

Socio-demographics and clinical characteristics 
The distribution of diagnoses was collected through medical records. Socio-demographics, such as marital status and educational background, along with alcohol and tobacco habits, were collected through questionnaires before the intervention in both the intervention and reference sample.

\section{Symptom severity}

Patient symptom severity was assessed with the Clinical Global Impression-severity (CGI-s) scale. CGI-s is a single-item clinician rating of the severity of the patient's symptoms in relation to the clinician's total experience of previous persons with the same diagnosis. Severity is rated on a sevenpoint Likert scale, ranging from $1=$ Normal, not ill at all, to $7=$ among the most extremely ill patients (Guy, 2000).

Health-related quality of life

HRQoL was assessed using the EQ5D-3L (EuroQol 5 Dimensions, hereafter referred to as EQ5D), a standardized instrument for measuring health status (Dolan, 1997). The EQ5D includes five items related to mobility, self-care, usual activities, pain/discomfort, and anxiety/depression. Each dimension has three different response options: 1) no problems, 2) moderate problems, and 3) extreme problems. The EQ5D scores were converted into a single summary EQ5D index quantifying health status. The index has a range of -0.594 , (lowest $\mathrm{HRQ}$ oL), to 1.000 , (highest $\mathrm{HRQ}$ oL), and has 243 possible health outcomes. The EQ5D also includes the EQ visual analog scale (EQ- VAS), a vertical scale ranging from $0=$ worst imaginable health state, to $100=$ best imaginable health state (Brooks, 1996).

\section{Metabolic risk factors}

Metabolic risk factors relevant to the metabolic syndrome were measured (Alberti et al 2009). Systolic and diastolic blood pressure was measured in the supine position after a resting period of five minutes. Body weight was measured using calibrated scales, with participants wearing indoor clothing, but no shoes. Height and waist circumference were measured to the nearest $\mathrm{cm}$, and BMI 
was calculated. Blood samples were drawn with the subjects fasting, and subsequently analyzed or calculated using routine methods at hospital laboratories. The laboratories were accredited according to a quality assurance system (Good Laboratory Practice; GLP). The blood samples presented are total cholesterol, HDL and LDL cholesterol, total triglycerides, and plasma glucose. Figure 1 provides a schematic overview of the study.

Insert Figure 1 here

\section{Participants}

The participants were recruited to the intervention by the HCs according to the inclusion and exclusion criteria assigned by the research team. The HCs had good knowledge about the patient's degree of disability from their regular work, and made a subjective assessment of whether the person had the cognitive ability to assimilate the intervention. In most cases, this meant a GAFvalue (American psychiatric association 1994) above 40. The intervention group consisted of 44 participants. The sampling for the study was purposeful (Patton, 2002). Inclusion criteria were; having a psychotic disorder according to ICD 10 (2010) and established metabolic syndrome in accordance with the International diabetes federation (IDF, 2006, Alberti et al., 2009), or at risk of developing the metabolic syndrome. Exclusion criteria were; being in an acute psychotic state according to a clinical assessment by the regular case managers, having a personality disorder or anorexia nervosa as primary diagnosis, and being addicted to alcohol and narcotics according to ICD 10 (2010). Persons over the age of 65 were excluded.

\section{Reference group}

The reference group of 776 persons was recruited from the Swedish national cohort database "Metabolic risk factors in psychosis". They were diagnosed with a psychotic disorder and received treatment as usual. In the reference group, two individuals per participant were matched $(n=84)$. 
They were matched for sex and BMI class (below 25, 25-29.99, 30 and over), i.e., normal weight, overweight, and obesity. We also aimed to find reference persons of as similar age as possible.

\section{Statistical analysis}

All statistical analyses were performed using SPSS 22.0 (SPSS Inc, Chicago, IL, USA). The level of statistical significance was set to: $p \leq 0.05$. Descriptive statistics are presented as mean (SD) unless otherwise stated. Comparisons within and between groups were performed using Student's paired and unpaired t-test. Wilcoxon and Mann-Whitney $\mathrm{U}$ tests were used when making comparisons of EQ5D. The three possible answers in the EQ5D have been dichotomized in order to present the relative frequency in per cent of those in the intervention group and the reference sample reporting some or extreme problems on each subscale. In addition, socio-demographic data on living conditions and educational level were dichotomized in order to prepare data for presentation. Pearson chi-square, and Fisher's exact test were analyzed in nominal data. There were a few internal drop-outs in the calculations and none have been substituted for. As for HDL cholesterol, there is less basic data as values from only 23 persons are available.

\section{Ethics}

The study participants received written and verbal information regarding voluntary participation, that the study material would be confidential, and that they could withdraw from the study without questions being asked, or their regular treatment being affected in any way. All patients gave their written informed consent. The procedures were in accordance with the Declaration of Helsinki of 1964, revised in 2008. The protocol was approved by the Regional Ethical Review Board at Linköping University.

\section{Results}

All who were enrolled in the study were included in the analysis, with two exceptions. One person underwent a gastric bypass operation during the intervention. Another person chose not to 
cooperate in the physical exercise or lifestyle counseling provided, thereby breaking the study protocol.

\section{Demographics and clinical characteristics at baseline}

The matching variables resulted in no statistically significant differences between the groups regarding sex, BMI class, or age at baseline (Table 1). Table 1 provides a baseline description of socio-demographic data, lifestyle factors, and distribution of diagnosis in the intervention group and reference sample.

Insert Table 1 here.

The participation rate in the short ( 9 sessions) and long (20 sessions) intervention shows that the participants in the short version participated in 8 sessions in mean, compared to 13 sessions in the longer version.

\section{HRQoL at baseline and the one- year follow-up}

There were statistically significant differences between the intervention group and reference sample in three of five subscales at baseline (Table 2). In the intervention group, problems in usual activities were more common $(p<0.001)$. The reference sample had statistically significantly more frequent problems in pain/discomfort $(p=0.001)$, and in anxiety/depression $(p<0.001)$ at baseline.

Insert Table 2 here

When comparing baseline and one year follow-up within groups, there were no statistically significant differences in either of the EQ5D subscales. There were no significant differences in the EQ-index within or between the groups when comparing baseline and the one-year follow-up.

In an examination of the current health state, the EQ-VAS score increased in the intervention group when comparing baseline and the one- year follow- up ( $p=0.05$ ) (FIG 2). There were no statistically 
significant differences $(p=0.47)$ when comparing changes between baseline and the one-year followup between groups (delta value).

Insert Figure 2 here

\section{Metabolic risk factors at baseline and the one- year follow-up}

All intervention participants displayed at least one IDF criterion (2006) for metabolic syndrome at baseline. Ninety-three per cent had elevated waist circumference, $42 \%$ had a systolic blood pressure above $130 \mathrm{mmHg}$, 39\% had a diastolic blood pressure above $85 \mathrm{mmHg}$, and $46 \%$ had a glucose value above 5,6 mmol/l. As for HDL cholesterol, we obtained baseline data in 23 intervention participants, of which one was treated with a statin. Of these, $70 \%$ had a low value in accordance with the definition of metabolic syndrome.

As shown in Table 3, HDL cholesterol demonstrated a statistically significant increase when comparing baseline and the one- year follow-up within the intervention group $(p=0.02)$. A significant increase was also found when comparing the change from baseline to one-year follow- up between the groups $(p=0.047)$.

At the one- year follow-up, women $(n=19)$ in the intervention group had significantly lower blood pressure than the reference sample. Female intervention participants lowered their systolic blood pressure by $3 \mathrm{mmHg}$ in mean.

Insert Table 3 here

\section{Discussion}

The aim of the study was to study the effects of a lifestyle intervention on HRQoL and metabolic risk factors in persons with psychosis. The most important result was the improvement of HRQoL demonstrated by the EQ-VAS within the intervention group. Previous research has shown that interventions based on group activities are efficient (Green et al., 2014, Bonfioli, et al., 2012, 
Verhaeghe et al., 2011, Happel et al., 2012), and that QoL is shown to be one of the variables most affected by interventions (Happel et al., 2012). Our intervention attempted to take a multifaceted grasp of lifestyle, here defined as physical activities, and education in lifestyle and nutrition. Previous research has described that physical activity improves quality of life in psychiatric patients (Knöchel et al., 2012). Another possible explanation for the improvement in the EQ-VAS is that the intervention could have contributed to social relations and changing the focus from illness to health. Many persons with mental health problems experience a sense of loneliness and a desire to belong to a social context (Granerud and Severinson, 2006, Wärdig et al., 2015). However, social cognitive deficits complicate the conditions for social interaction (Fiszdon et al., 2013). If people manage to participate and maintain social relationships, they can probably be strengthened. This is why social networks can have an impact on health state. It is, however, important to emphasize that the EQVAS observed in the intervention group at the one- year follow-up was still below the average population norm, which is 77 in the age group 40-49 years, the group that best matched the average age of our participants (45.5 years) (Measuring self-reported population health: An international perspective based on EQ5D, 2004).

We also reached a statistically significant improvement in HDL cholesterol, both within group and in comparison with the reference sample. Based on the content of the intervention, it is possible that the improvement of HDL cholesterol is a consequence of changed eating and exercise habits (Andersen and Luz Fernandez, 2013). Of all participants with available HDL cholesterol data, only one person was treated with a statin during the intervention. However, it is important to note that the $\mathrm{HDL}$ cholesterol concentration was still below recommendations for women (above $1.3 \mathrm{mmol} / \mathrm{L}$ ), and on the low side of recommendations for men (above $1.0 \mathrm{mmol} / \mathrm{L}$ ) (Alberti et al., 2009). Another significant finding was that women in the intervention group had significantly lower blood pressure than the reference sample at the one- year follow-up, which could also be a result of increased physical activity in the intervention. Even though much is unknown about the maintenance of good health behaviors after an intervention (Lin et al., 2014), research has shown 
that physical activity in various forms has a lowering effect on blood pressure (Pal et al., 2013). There is also research in support of women following self-care advice to a greater extent than men, particularly preventive measures and dietary advice (Szymczyk et al., 2013).

In an evaluation of a lifestyle intervention for persons with psychosis, such as the present study, it is relevant to discuss realistic goals. The best-case scenario would be to improve or at least maintain HRQoL and not worsen the metabolic risk factors. It is a well-known fact that it is very difficult to change lifestyles, and in that light, even small changes in risk factors may be important (AlverezJimenez et al., 2008). As for waist circumference, one of the metabolic risk factors of the metabolic syndrome (Alberti et al., 2009), 93\% of the intervention participants had a waist circumference exceeding the limit value at baseline. Recent research has revealed that established obesity will hamper interventions to reduce and maintain body weight through biological adaptations designed to prevent starvation, which can probably explain the often poor long-term success rates of lifestyle modifications (Ochner et al., 2015). Therefore, it is important to implement preventive actions earlier in the disease process, before obesity is established. Several adequate guidelines for screening and monitoring metabolic risks are available (De Hert et al., 2011). However, they are not used to a desirable extent, and most patients still do not receive adequate testing (Mitchell et al., 2012).

In accordance with previous research (Druss et al., 2011, Robson and Gray, 2007), the participants in our study displayed a high frequency of metabolic risk factors, and it is well known that changing lifestyles is particularly challenging for persons with psychosis. The symptoms affect the ability to start living healthily (Von Hausswolff-Juhlin et al., 2009). According to the CGI-S scale (Guy, 2000), the intervention participants had a worse symptom profile than the reference sample. Recent research has demonstrated that negative symptoms in persons with psychosis are significantly associated with lower levels of motivation to perform physical activity (Vancampfort et al., 2015). Presence of psychiatric symptoms may be one reason for not starting to live healthily (Wärdig et al., 2013). 
Bearing these problems in mind, an intervention developed to meet the needs of this group should be suitable (Porsdal, 2010). However, it is possible that, based on current symptoms, some could have had problems assimilating the information, or did not have the power to change, which could have affected the outcome.

The previously mentioned research findings reporting how difficult it is to tackle obesity if it is already established (Ochner et al., 2015) describe a major challenge. Future research needs to continue to search for approaches designed to suit this group, this is justified by the high mortality and comorbidity rates in persons with psychosis (Wahlbeck et al., 2011). To create opportunities for real and sustained changes, it is necessary to find evidence-based approaches that are feasible to implement in a clinical context, and embrace a holistic approach that includes both physical and mental health. This assumes a compensated self-care, where health care professionals offer necessary support (Riegel et al., 2012). Sebastian and Beer (2007) described that physical health problems partly arise because the psychiatric specialists prioritize psychiatric problems. It may be argued that the health care system has a structural discrimination (Thornicroft et al., 2009), that perhaps creates a sense that the battle already is lost.

\section{Limitations}

The main limitation of the study is the different durations of the intervention. Due to organizational limitations, it was not possible to perform an intervention with the same number of meetings in the two regions. However, inclusion from two different geographical regions made it possible to include more participants and reduce the risk of an outcome colored by a particular local culture. It is also important to stress that the intervention was based on the same concept, "Solutions for wellness" (Porsdal et al., 2010), and performed in an identical way, except for the number of meetings. As the aim of this study was to study the effects of a lifestyle intervention on health-related quality of life and metabolic risk factors in persons with psychosis, the exact number of meetings was considered less important. Earlier research has found that these persons often have difficulties with attendance 
(Richardson et al 2005 b), and a comparison between the short and long intervention shows that the number of completed intervention sessions were relatively similar, on average 8 vs. 13 . Another limitation is that due to the different intervention durations, the amount of time between the end of the intervention and the one-year follow-up differed between participants, creating somewhat different conditions. Research has shown that it may take more time before persons with psychosis improve in body weight (Daumit et al., 2013).

A further reflection concerns the reference sample's development between baseline and follow-up. Although there were few positive significant differences between baseline and follow-up, it can be concluded that the reference sample did not demonstrate a poorer outcome in general. This could be explained in terms of external validity (Polit and Beck 2012). It should be seen as a strength that data was collected during the same period of time, when prevailing ideas regarding lifestyle were equally present in both groups.

\section{Conclusions}

The current study demonstrates that a lifestyle intervention improves HRQoL when comparing EQVAS at baseline and the one- year follow- up. The intervention also resulted in small improvements in metabolic risk factors, such as the significantly increased HDL cholesterol, as well as the lowered blood pressure in female participants, compared with female references at the one- year follow-up. Although small changes can be valuable in the context studied, it can be concluded that our intervention was not powerful enough to influence the metabolic risk factors to a greater extent.

\section{Declaration of interest}

The authors report no conflicts of interest. 


\section{References}

Alberti, KG., Eckel, R.H., Grundy, S.M., Zimmet, P.Z., Cleeman, J.I., Donato, K.A., Fruchart, JC., James W.P., Loria, C.M., Smith, S.C Jr. (2009). Harmonizing the metabolic syndrome: a joint interim statement of the International Diabetes Federation Task Force on Epidemiology and Prevention; National Heart, Lung, and Blood Institute; American Heart Association; World Heart Federation; International Atherosclerosis Society; and International Association for the Study of Obesity. Circulation 120: 1640-1645.

Àlvarez-Jiménez, M., Hetrick, S.E., Gonzalez-Blanch, C., Gleeson, J.F., McGorry, P.D. (2008). Nonpharmacological management of antipsychotic-induced weight gain: systematic review and metaanalysis of randomized controlled trials. The British Journal of Psychiatry 193:101-107.

American Psychiatric Association (2013) Diagnostic and statistical manual of mental disorders, 5th ed, DSM-5 ${ }^{\mathrm{TM}}, \mathrm{DSM}-5^{\circledR}$

American Psychiatric Association (1994) Diagnostic and statistical manual of mental disorders. 4th ed, DSM-IV. Washington DC: APA.

Andersen, C.J., \& Luz Fernandez, M. (2013). Dietary approaches to improving atheroprotective HDL functions. Food Funct 4:1304-1313.

Baker, F., \& Intagliata, J. (1982) Quality of life in the evaluation of community support systems. Eval Program Plann, 5, 69-79.

Becker, W., Lyhne, N., Pedersen, A.N., Aro, A., Fogelholm, M., Pho'rsdottir ,I., Alexander, J., Anderssen, S.A., Meltzer, H.M., Pedersen, J.I. (2004). Nordic Nutrition Recommendations; integrating nutrition and physical activity. Scandinavian Journal of Nutrition 48: 178-187. 
Bonfioli, E., Berti, L., Goss, C., Muraro, F., Burti, L. (2012). Health promotion lifestyle interventions for weight management in psychosis: a systematic review and meta-analysis of randomized controlled trials. BMC Psychiatry 12: 12 pages.

Bradshaw, T., Lovell, K., Harris, N. (2005). Healthy living interventions and schizophrenia: a systematic review. Journal of Advanced Nursing 49:634-654.

Brooks, R. (1996). EuroQol: the current state of play. Health Policy 37:53-72.

Brown, A.S., \& MCGrath, J.J. (2011). The prevention of schizophrenia. Schizophr Bull 37:257-261.

Daumit, G.L., Dickerson, F.B., Wang, N.Y., Dalcin, A., Jerome, G.J., Anderson, C.A.M., Young, D.R., Frick, K.D., Yu, A., Genussa, III, J.V., Oefinger, M., Crum, R.M., Charleston, J., Casagrande, S.S., Guallar, E., Goldberg, R.W., Campbell, L.M., Appel, L.J. (2013). A behavioral weight loss intervention in persons with serious mental illness. The New England Journal of Medicine 368: 1594-1602.

De Hert, M., Vancampfort, D., Corell, C.U., Mercken, V., Peuskens, J., Sweers, K., van Winkel, R., Mitchell, A.J. (2011). Guidelines for screening and monitoring of cardiometabolic risk in schizophrenia: systematic evaluation. The British Journal of Psychiatry 199: 99-105.

Dolan, P. (1997). Modeling valuations for EuroQol health states. Medical care 35:1095-1108.

Druss, B.G., Zhao, L., Von Esenwien, S., Morrato, E.H., Marcus, S.C. (2011). Understanding excess mortality in persons with mental illness: 17 year follow up of a nationally representative US survey. Med Care 49: 599-604.

Edward, K.L., Rasmussen, B., Munro, I. (2010). Nursing care of clients treated with atypical antipsychotics who have a risk of developing metabolic instability and/or type 2 diabetes. Archives of Psychiatric Nursing 24: 46-53.

Faulkner, G., Soundy, A.A., Lloyd, K. (2003). Schizophrenia and weight management: a systematic review of interventions to control weight. Acta Psychiatr Scand 108:324-332. 
Fernández-San-Martín, M.I., Martín-López, L.M., Masa-Font, R., Olona-Tabuena, N., Roman, Y., Martin-Royo, J., Oller-Canet, S., González-Tejón, S., San-Emererio, L., Barroso-Garcia, A., VinasCabrera, L., Flores-Mateo, G. (2014). The effectiveness of lifestyle interventions to reduce cardiovascular risk in patients with severe mental disorders: Meta-analysis of intervention studies. Community Ment Health J 50:81-95.

Fiszdon, J.M., Fanninga, J.R., Johannesen, J.K., Bell, M.D. (2013). Social cognitive deficits in schizophrenia and their relationship to clinical and functional status. Psychiatry Res 30: 11 pages.

Foldemo, A., Wärdig, R., Bachrach-Lindström, M., Edman, G., Holmberg, T., Lindström, T., Valter, L., Ösby, U. (2014). Health-related quality of life and metabolic risk in patients with psychosis. Schizophrenia Research 152:295-299.

Granerud, A., Severinsson, E. (2006). The struggle for social integration in the community - the experiences of people with mental health problems. Journal of Psychiatric and Mental Health Nursing 13:288-293.

Green, C.A., Yarborough, B.J., Leo, M.C., Stumbo, S.P., Janoff, S.L., Perrin, N.A., Nichols, G.A, Stevens, V. (2014). The STRIDE weight loss and lifestyle intervention for individuals taking antipsychotic medication: A randomized study. Am J Psychiatry 172:71-81.

Guy, W. (2000). Clinical Global Impression (CGI). In Handbook of psychiatric measures Edited by: Rush AJ. American Psychiatric Association, Washington DC, 100-102.

Happell, B., Davies, C., Scott, D. (2012). Health behaviour interventions to improve physical health in individuals diagnosed with a mental illness: A systematic review. International Journal of Mental Health Nursing 21:236-247.

Heald, A. (2010). Physical health in schizophrenia: a challenge for antipsychotic therapy. European Psychiatry 25:6-11. 
International Classification of Diseases. (ICD-10 2010). Available at:

http://www.who.int/classifications/icd/en/

International Diabetes Federation. (2006). The IDF consensus worldwide definition of the metabolic syndrome Available at: http://www.idf.org/webdata/docs/IDF_Meta_def_final.pdf (accessed 9 June 2014).

Knöchel, C., Oertel-Knöchel, V., O’Dwyer, L., Prvulovic, D., Alves, G., Kollmann, B., Hampel, H. (2012). Cognitive and behavioural effects of physical exercise in psychiatric patients. Progress in Neurobiology 96:46-68.

Lin, J.S., O'Connor, E., Evans, C.V., Senger, C.A., Rowland, M.G., Groom, H.C. (2014). Behavioral counseling to promote a healthy lifestyle in persons with cardiovascular risk factors: A systematic review for the U.S. preventive services task force. Ann Intern Med 161:568-578.

Lowe T., \& Lubos, E. (2008). Effectiveness of weight management interventions for people with serious mental illness who receive treatment with atypical antipsychotic medications. A literature review. Journal of Psychiatric and Mental Health Nursing 15:857-863.

. Edited by Agota Szende and Alan Williams Available:http://www.euroqol.org/fileadmin/ Measuring self-reported population health: An international perspective based on EQ5D. (2004). An Instrument to value Health from the EuroQol Group user_upload/Documenten/PDF/Books/Measuring_SelfReported_Population_Health_-_An_International_Perspective_based_on_EQ-5D.pdf Mestdagh, A., \& Hansen, B. (2014). Stigma in patients with schizophrenia receiving community mental health care: a review of qualitative studies. Soc Psychiatry Epidemiol 49:79-87.

Meyer, J.M., \& Stahl, S.M. (2009). The metabolic syndrome and schizophrenia. Acta Psychiatr Scand, 119:4-14 
Mitchell, A.J., Delaffon, V., Vancampfort, D., Corell, C.U., De Hert, M. (2012). Guideline concordant monitoring of metabolic risk in people treated with antipsychotic medication: systematic review and meta-analysis of screening practices. Psychological Medicine 42:125-47.

Newcomer, J.W. (2006). Medical risk in patients with bipolar disorder and schizophrenia. The Journal of Clinical Psychiatry 67:25-30.

Ochner, C.N., Tsai, A.G., Kushner, R.F., Wadden, T.A. (2015). Treating obesity seriously: when recommendations for lifestyle change confront biological adaptations. Lancet Diabetes Endocrinol 3:232-234.

Pal, S., Radavelli-Bagatini, S., Ho, S. (2013). Potential benefits of exercise on blood pressure and vascular function. Journal of the American Society of Hypertension 7:494-506.

Papanastasiou, E. (2012). Interventions for the metabolic syndrome in schizophrenia: a review. Therapeutic Advances in Endocrinology and Metabolism 3:141-162.

Pearsall, R., Smith, D.J., Pelosi, A., Geddes, J. (2014). Exercise therapy in adults with serious mental illness: a systematic review and meta-analysis. BMC Psychiatry 14:17 pages.

Pickens, J.M. (1999). Living with serious mental illness: The desire for normalcy. Nursing Science Quarterly 3:233-239.

Polit, D.F., \& Beck, C.T. (2012). Nursing research. Generating and assessing evidence for clinical practice. Ninth edition. Wolter Kluwer Health/Lippincott Williams \& Wilkins.

Porsdal, V., Beal, C., Kleivenes, O.K., Martinsen, E.W., Lindström, E., Nilsson, H., Svanborg, P. (2010). The Scandinavian Solutions for Wellness study - a two arm observational study on the effectiveness of lifestyle intervention on subjective well-being and weight among persons with psychiatric disorders. BMC Psychiatry 10: 12 pages. 
Richardson, C.R., Faulkner, G., McDevitt, J., Skrinar, G.S., Hutchinson, D.S., Piette, J.D. (2005 a). Integrating physical activity into mental health services for persons with serious mental illness. Psychiatric Services 56: 324-331.

Richardson, C.R., Avripas, S.A., Neal, D.L., Marcus, S.M. (2005 b). Increasing Lifestyle Physical Activity in Patients with Depression or Other Serious Mental Illness. Journal of Psychiatric Practice 11:379388.

Riegel, B., Jaarsma, T., Stromberg, A. (2012). A middle-range theory of self-care of chronic illness. Advances in Nursing Science 35:194-204.

Robson, D., \& Gray, R. (2007). Serious mental illness and physical health problems: A discussion paper. International Journal of Nursing Studies 44:457-466.

Roohafza, H., Sadeghi, M., Talaei, M., Pourmoghaddas, Z., Sarrafzadegan, N. (2012). Psychological status and quality of life in relation to the metabolic syndrome: Isfahan Cohort Study. International Journal of Endocrinology Vol 2012: 1-5.

Rummel-Kluge, C., Schwarz, S., Hunger, H., Schmid, F., Asenjo Lobos, C., Kissling, W., Davis, J.M., Leucht, S. (2010). Head-to-head comparisons of metabolic side effects of second generation antipsychotics in the treatment of schizophrenia: a systematic review and meta-analysis. Schizophrenia Research 123:1-13.

Saarni, S.I., Suvisaari, J., Sintonen, H., Pirkola, S., Koskinen, S., Aromaa, A., Lönnqvist, J. (2007). Impact of psychiatric disorders on health-related quality of life: general population survey. The British Journal of Psychiatry 190:326-332.

Saarni, S.I., Viertiö, S., Perälä, J., Koskinen, S., Lönnqvist, J., Suvisaari, J. (2010). Quality of life of people with schizophrenia, bipolar disorder and other psychotic disorders. The British Journal of Psychiatry 197: 386-394. 
Sebastian, C., Beer, D.M. (2007). Physical health problems in schizophrenia and other serious mental illnesses. Journal of Psychiatric Intensive Care 3:101-112.

Szymczyk, I., Wojtyna, E., Lukas, W., Kępa, J., Pawlikowska, T. (2013). How does gender influence the recognition of cardiovascular risk and adherence to self-care recommendations?: a study in polish primary care. BMC Family Practice 14: 10 pages.

Thornicroft, G., Brohan, E., Rose, D., Sartorius, N. (2009). The INDIGO study group global pattern of anticipated and experienced discrimination against people with schizophrenia. Lancet 373:408-415.

Vancampfort, D., De Hert, M., Stubbs, B., Ward, P.B., Rosenbaum, S., Soundy, A., Probst, M. (2015). Negative symptoms are associated with lower autonomous motivation towards physical activity in people with schizophrenia. Comprehensive Psychiatry 56:128-132.

Verhaeghe, N., De Maeseneer, J., Maes, L., Van Heeringen, C., Annemans, L. (2011). Effectiveness and cost-effectiveness of lifestyle interventions on physical activity and eating habits in persons with severe mental disorders: A systematic review. International Journal of Behavioral Nutrition and Physical Activity 8: 12 pages.

von Hausswolff-Juhlin, Y., Bjartveit, M., Lindström, E., Jones, P. (2009). Schizophrenia and physical health problems. Acta Psychiatr Scand 119:15-21.

Wahlbeck, K., Westman, J., Nordentoft, M., Gissler, M., Munk Laursen, T. (2011). Outcomes of Nordic mental health systems: life expectancy of patients with mental disorders. The British Journal of Psychiatry 199: 453-458.

WMA General Assembly. 2008. WMA Declaration of Helsinki - Ethical Principles for Medical Research Involving Human Subjects, The World Medical Association.

Wärdig, R., Bachrach-Lindström, M., Foldemo, A., Lindström, T., Hultsjö, S. (2013). Prerequisites for a 
healthy lifestyle- experiences of persons with psychosis. Issues in Mental Health Nursing 34:602-610.

Wärdig, R., Bachrach-Lindström, M., Hultsjö, S., Lindström, T., Foldemo, A. (2015) Persons with psychosis perceptions of participating in a lifestyle intervention. Journal of Clinical Nursing 24, 18151824. 


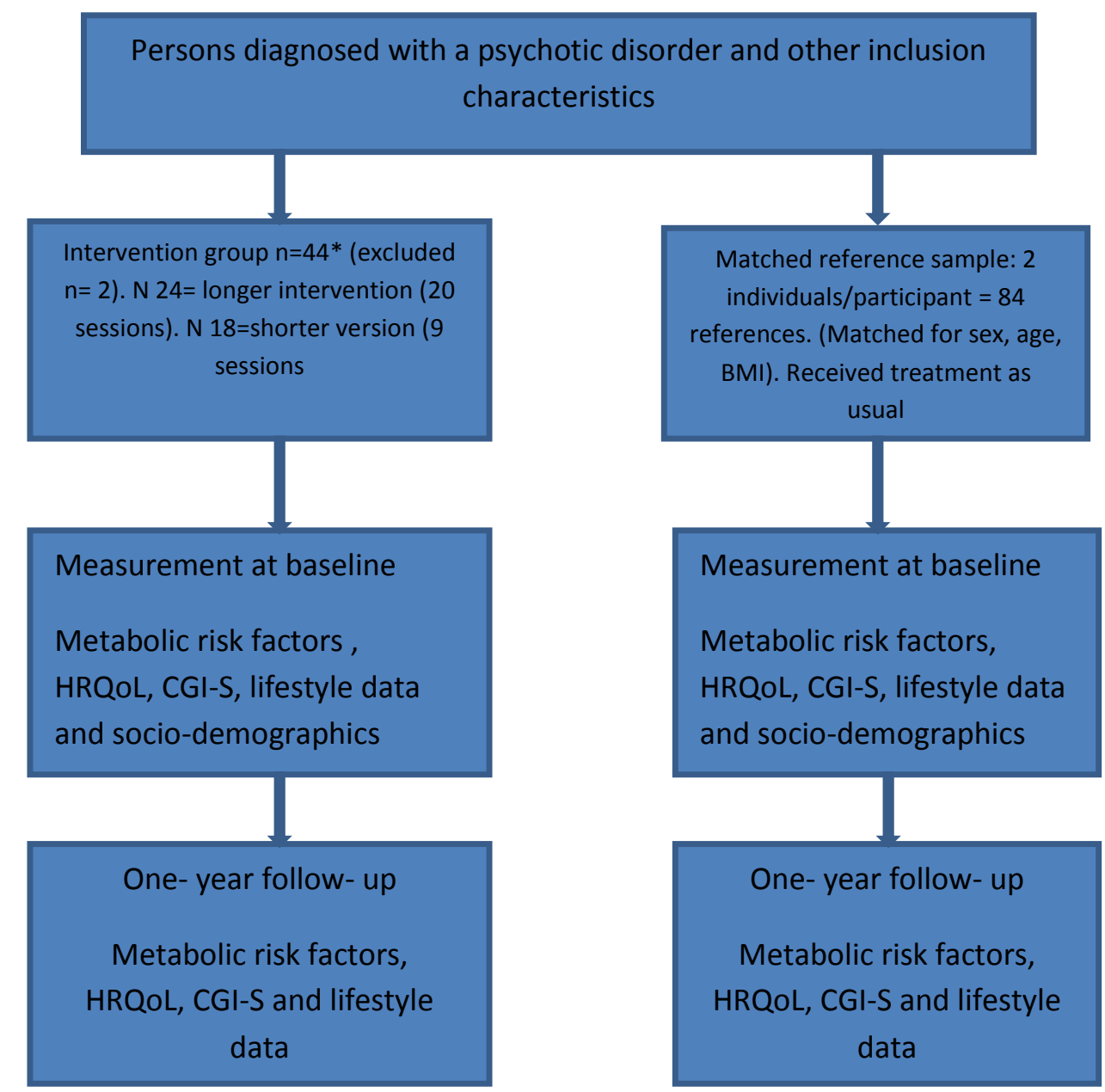

Figure 1. Schematic overview of the study

*Excluded from analysis=2 due to 1) Gastric Bypass, 2) One participant choosing not to cooperate in the physical exercise or lifestyle counseling provided. 
Table 1. Clinical characteristics at baseline in intervention ( $n=42)$ and reference sample $(n=84)$. Mean and SD are given unless otherwise stated.

\begin{tabular}{|c|c|c|c|}
\hline Variable & $\begin{array}{l}\text { Intervention } \\
\text { group } \\
n=42\end{array}$ & $\begin{array}{l}\text { Reference } \\
\text { sample } \\
n=84\end{array}$ & P value \\
\hline Age (years) & $45.5(10.2)$ & $47.2(8.7)$ & 0.32 \\
\hline Duration of illness (years) & $18(11.7)$ & $20(9.4)$ & 0.30 \\
\hline Female gender (\%) & 45 & 45 & 1.00 \\
\hline Living alone (\%) & 69 & 67 & 0.99 \\
\hline University or higher education (\%) & 21 & 38 & 0.06 \\
\hline At least one risk factor for Mets (\%)* & 100 & 100 & \\
\hline CGI-S & $4.14(1.14)$ & $3.58(1.11)$ & 0.007 \\
\hline Teetotallers (\%) & 51 & 71 & 0.03 \\
\hline Smoking (\%) & 33 & 38 & 0.60 \\
\hline Snuff (\%) & 19 & 21 & 0.73 \\
\hline Schizophrenia (\%) & 36 & 57 & \\
\hline Schizoaffective disorder (\%) & 24 & 7 & \\
\hline Delusional disorder (\%) & 7 & 8 & \\
\hline Psychosis NOS (\%) & 12 & 20 & \\
\hline Bipolar disorder (\%) & 21 & 7 & \\
\hline \multicolumn{4}{|c|}{ *Metabolic syndrome according to IDF (2006) } \\
\hline
\end{tabular}

Bold value denote significance 
Table 2. EQ5D subscales in the intervention group $(n=42)$ and in the reference sample $(n=84)$ at baseline and 12 month. The relative frequency in percent of those reporting some or extreme problems on each subscale is given

\begin{tabular}{lcccccc}
\hline & \multicolumn{3}{l}{ Baseline } & \multicolumn{3}{c}{12 months } \\
\hline EQ-5D subscales & $\begin{array}{c}\text { Intervention } \\
\text { group }\end{array}$ & $\begin{array}{l}\text { Reference } \\
\text { sample }\end{array}$ & P-value & $\begin{array}{c}\text { Intervention } \\
\text { group }\end{array}$ & $\begin{array}{c}\text { Reference } \\
\text { sample }\end{array}$ & p-value \\
\hline Mobility (\%) & 19 & 20 & 0.87 & 14 & 21 & 0.51 \\
Self-care (\%) & 5 & 5 & 1.0 & 11 & 4 & 0.20 \\
Usual activities (\%) & 62 & 27 & $<0.001$ & 54 & 32 & $\mathbf{0 . 0 2 3}$ \\
Pain/discomfort (\%) & 29 & 61 & $\mathbf{0 . 0 0 1}$ & 14 & 51 & $<0.001$ \\
Anxiety/depression (\%) & 21 & 71 & $<0.001$ & 22 & 64 & $<0.001$ \\
\hline
\end{tabular}

Bold value denote significance 


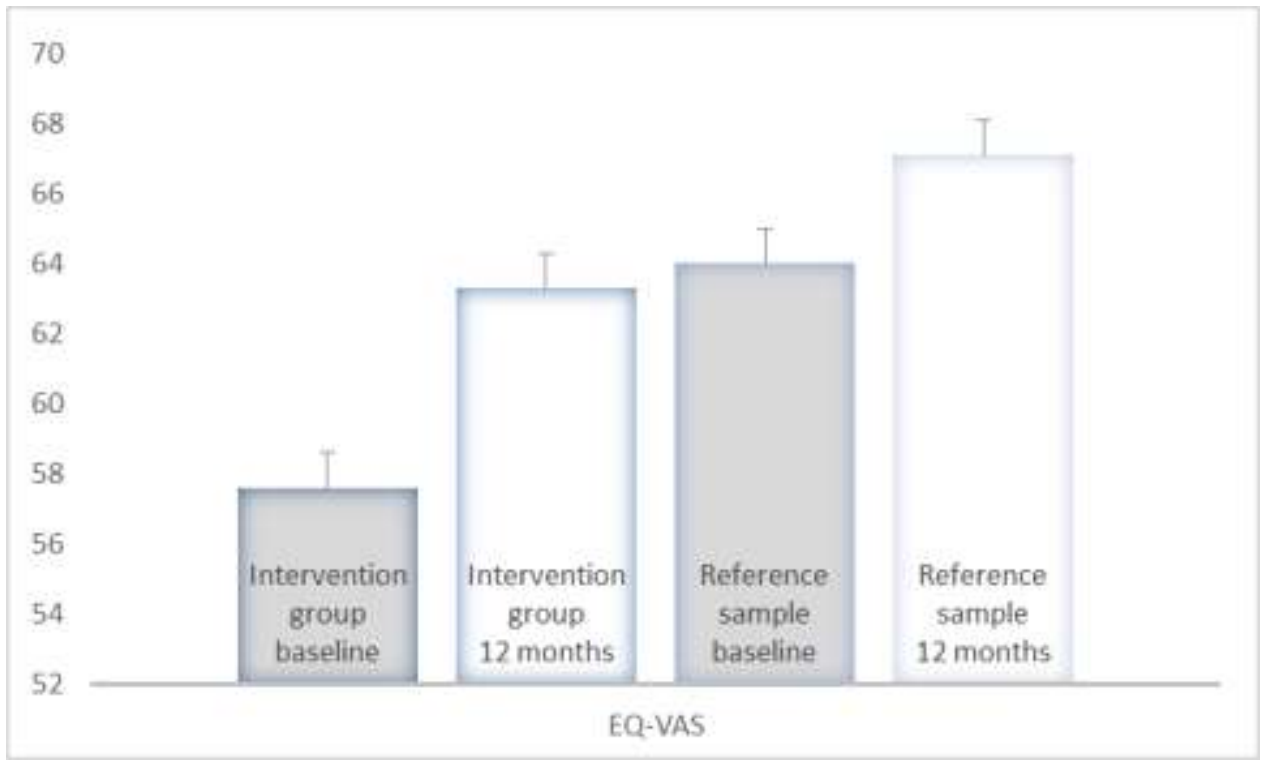

Figure 2. EQ-VAS in intervention and reference sample at baseline and the one-year follow up. 
Table 3. Metabolic risk factors in the intervention ( $n=42)$ and reference sample $(n=84)$. Mean and SD are presented.

\begin{tabular}{|c|c|c|c|c|c|c|c|}
\hline & \multicolumn{3}{|c|}{ Intervention group } & \multicolumn{4}{|c|}{ Reference sample } \\
\hline & Baseline & $\begin{array}{l}12 \\
\text { months }\end{array}$ & $\begin{array}{l}\text { P-value } \\
0-12 \\
\text { months } \\
\text { within } \\
\text { group }\end{array}$ & Baseline & $\begin{array}{l}12 \\
\text { months }\end{array}$ & $\begin{array}{l}\text { P-value } \\
0-12 \\
\text { months } \\
\text { within } \\
\text { group }\end{array}$ & $\begin{array}{l}\text { P-value } \\
\text { for } \\
\text { change } \\
\text { between } \\
\text { groups } \\
0-12 \\
\text { months }\end{array}$ \\
\hline Body weight (kg) & $94.9(15.5)$ & $\begin{array}{c}96.1 \\
(14.6)\end{array}$ & 0.57 & $\begin{array}{c}98.3 \\
(15.6)\end{array}$ & $\begin{array}{l}97.3 \\
(16)\end{array}$ & 0.15 & 0.21 \\
\hline Waist (cm) & $\begin{array}{l}110.7 \\
(12.3)\end{array}$ & $\begin{array}{l}109.4 \\
(11.2)\end{array}$ & 0.10 & $\begin{array}{l}109.4 \\
(11.9)\end{array}$ & $\begin{array}{l}108.1 \\
(12.8)\end{array}$ & 0.13 & 0.63 \\
\hline $\mathrm{BMI} \mathrm{kg} /\left(\mathrm{cm}^{2}\right)$ & $32.4(5.02)$ & $\begin{array}{c}32.7 \\
(4.76)\end{array}$ & 0.65 & $32(4.75)$ & $\begin{array}{c}31.7 \\
(5.01)\end{array}$ & 0.19 & 0.41 \\
\hline $\begin{array}{l}\text { Systolic blood-pressure } \\
(\mathrm{mm} / \mathrm{Hg})\end{array}$ & $\begin{array}{l}127.4 \\
(19.5)\end{array}$ & $\begin{array}{l}124.4 \\
(17.6)\end{array}$ & 0.38 & $\begin{array}{l}128.1 \\
(17.2)\end{array}$ & $\begin{array}{l}128.8 \\
(14.5)\end{array}$ & 0.70 & 0.30 \\
\hline $\begin{array}{l}\text { Diastolic blood-pressure } \\
(\mathrm{mm} / \mathrm{Hg})\end{array}$ & $81.8(11.4)$ & $\begin{array}{c}81.5 \\
(12.5)\end{array}$ & 0.54 & $\begin{array}{c}84.6 \\
(12.3)\end{array}$ & $\begin{array}{c}84.3 \\
(11.7)\end{array}$ & 0.80 & 0.75 \\
\hline $\begin{array}{l}\text { Fasting plasma glucose } \\
(\mathrm{mmol} / \mathrm{l})\end{array}$ & $5.98(1.75)$ & $\begin{array}{l}5.95 \\
(1.4)\end{array}$ & 0.89 & $\begin{array}{c}5.46 \\
(0.78)\end{array}$ & $\begin{array}{c}5.21 \\
(1.48)\end{array}$ & 0.09 & 0.60 \\
\hline Total Cholesterol (mmol/l) & $5.53(1.16)$ & $\begin{array}{c}5.33 \\
(0.97)\end{array}$ & 0.45 & $\begin{array}{c}5.37 \\
(0.91)\end{array}$ & $\begin{array}{l}5.38 \\
(1.05)\end{array}$ & 0.98 & 0.44 \\
\hline Triglycerids (mmol/l) & $2.16(1.47)$ & $\begin{array}{c}2.84 \\
(2.33)\end{array}$ & 0.28 & $\begin{array}{c}1.91 \\
(1.19)\end{array}$ & $\begin{array}{c}1.66 \\
(0.84)\end{array}$ & 0.05 & 0.03 \\
\hline LDL Cholesterol (mmol/l) & $3.55(1.10)$ & $\begin{array}{c}3.25 \\
(0.80)\end{array}$ & 0.35 & $\begin{array}{c}3.48 \\
(0.82)\end{array}$ & $\begin{array}{c}3.57 \\
(0.93)\end{array}$ & 0.27 & 0.14 \\
\hline HDL Cholesterol (mmol/l) & $1.03(0.19)$ & $\begin{array}{c}1.11 \\
(0.19)\end{array}$ & 0.02 & $\begin{array}{c}1.11 \\
(0.26)\end{array}$ & $\begin{array}{c}1.08 \\
(0.27)\end{array}$ & 0.27 & 0.047 \\
\hline $\begin{array}{l}\text { Bold value denote } \\
\text { significance }\end{array}$ & & & & & & & \\
\hline
\end{tabular}

